\title{
Role of prophylactic hemoclip placement in prevention of delayed post-polypectomy bleeding for large colon polyps: a meta-analysis of randomized controlled trials
}

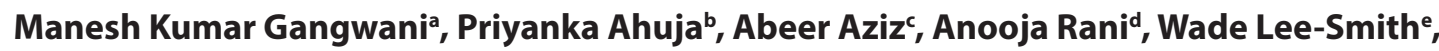 \\ Muhammad Aziz
}

Mercy Hospital St. Louis, MO, USA; Shaheed Mohtarma Benazir Bhutto University, Larkana, Pakistan; Aga Khan University, Karachi, Pakistan; Dow University of Health Sciences, Pakistan; University of Toledo Medical Center, Toledo, Ohio, USA

Abstract

\begin{abstract}
Background Polypectomy is a widely used and effective procedure to treat precancerous polyps. Delayed post-polypectomy bleeding (DPPB), a common complication of polypectomy, may diminish the utility of this procedure. Previous data on the efficacy of hemoclips has been conflicting, therefore we aimed to collectively evaluate and analyze the data to reach a definitive conclusion on the efficacy of using hemoclips to prevent incidences of DPPB in patients with large polyps ( $\geq 10 \mathrm{~mm}$ ).
\end{abstract}

Methods We identified a total of 261 studies based on our previously defined search strategy. After screening, we included 6 randomized controlled trials. A meta-analysis was performed comparing the use of prophylactic application of hemoclips to a standard group without prophylactic clip placement for large polyps.

Results We found a statistically significant reduction in the incidence of DPPB when using hemoclips for large polyps. The overall incidence of DPPB was lower in the hemoclip group compared to the standard group for all large polyps $\geq 10 \mathrm{~mm}$ (relative risk $0.51,95 \%$ confidence interval $\left.0.35-0.75 ; \mathrm{P}=0.01 ; I^{2}=0 \%\right)$.

Conclusions The use of hemoclips in achieving hemostasis for large polyps has a beneficial effect and appears to prevent DPPB. This reinforces the routine clinical practice of using hemoclips in polypectomy procedures.

Keywords Delayed post-polypectomy bleeding, large polyps, colonoscopy

Ann Gastroenterol 2021; 35 (1): 1-7

\section{Introduction}

Colorectal cancer accounts for $9.2 \%$ of deaths amongst cancer patients globally and a strong emphasis is placed on

Department of anternal Medicine, Mercy Hospital St. Louis, MO, USA (Manesh Kumar Gangwani); ${ }^{b}$ Medicine, Shaheed Mohtarma Benazir Bhutto University, Larkana, Pakistan (Priyanka Ahuja); ${ }^{\mathrm{c} M e d i c i n e, ~ A g a ~ K h a n ~ U n i v e r s i t y, ~ K a r a c h i, ~ P a k i s t a n ~(A b e e r ~ A z i z) ; ~}$ ${ }^{\mathrm{d}}$ Medicine, Dow University of Health Sciences, Pakistan (Anooja Rani); ${ }^{e}$ Gastroenterology, University of Toledo Medical Center, Toledo, Ohio, USA (Wade Lee-Smith); ' Gastroenterology, University of Toledo Medical Center, Ohio, USA (Muhammad Aziz)

Conflict of Interest: None

Correspondence to: Manesh Kumar Gangwani, MD,

Mercy Hospital St. Louis, St. Louis, Missouri, USA, 63141

e-mail: gangwani.manesh@gmail.com

Received 14 July 2020; accepted 27 November 2020; published online 26 February 2021

DOI: https://doi.org/10.20524/aog.2021.0602 screening to prevent the disease [1,2]. Removal of precancerous polyps by colonoscopy and polypectomy are widely accepted as methods of prevention and have been highly effective in reducing colorectal cancer incidence and mortality [2,3]. However, these procedures carry certain risks. Delayed postpolypectomy bleeding (DPPB), defined as bleeding occurring after removal of the colonoscope, has an incidence rate ranging between 0.2 and $2 \%$, with numbers reported to be higher for larger polyps $[4,5]$.

Several risk factors for DPPB have been identified and can be classified into: polyp-related (e.g., size, type); procedure related (e.g., use of electrocautery); and patient-related (e.g., age, anticoagulant use) [5]. Amongst these, polyp size is a key risk factor since removal of polyps $<10 \mathrm{~mm}$ carry a lower incidence of DPPB while removal of larger polyps $(\geq 10 \mathrm{~mm})$ results in an increased risk [3,6]. Additionally, with every $1 \mathrm{~mm}$ increase in the diameter of a polyp, the chances of hemorrhage increase by $9 \%$ [2].

Prophylactic clipping, a routinely performed endoscopic procedure, can help reduce the incidence of DPBB by 
achieving hemostasis through mechanical means [7]. While there is abundant data on the efficacy of hemoclips, there is no definitive answer on the success of prophylactic clipping for large polyps (LP) due to conflicting results [4]. Our study aimed to analyze the currently available data and evaluate the efficacy of hemoclip placement as a prophylactic measure to prevent DPPB for large colon polyps $\geq 10 \mathrm{~mm}$.

\section{Materials and methods}

\section{Search strategy / article screening / selection}

A comprehensive search of the following databases was conducted from inception through March 17, 2020: PubMed/ Medline, Embase, Cochrane Central Register of Controlled Trials, and Web of Science Core Collection. Search strategy was created using one database by an experienced librarian (W.L.S.) and translated into syntax/vocabulary of other databases. A hand search was not performed. The search strategy was cross checked by another reviewer (M.A.). The screening of articles and selection was performed by 2 independent reviewers (M.G. and M.A.) and any discrepancy in study selection was solved through mutual discussion. The screening was initially conducted using the title and abstracts and full text of relevant articles were further scrutinized. The bibliography of finalized articles was also screened to broaden the literature review. A detailed search strategy using EMBASE is highlighted in Supplementary Table 1.

\section{Inclusion and exclusion criteria}

We used the following inclusion criteria for selecting studies: 1) patients undergoing polypectomy for LPs $\geq 10 \mathrm{~mm}$; 2) intervention: application of prophylactic hemoclip to close the defect after polypectomy - hemoclip group (HG); 3) comparison of standard polypectomy without prophylactic application of hemoclip to a standard group (SG); and 4) outcomes of DPPB, defined as a significant bleeding event noted within the specified follow-up period. Only randomized controlled trials (RCTs) published as full-length manuscripts were included. No restriction to language or publication date was applied. Abstracts and other study designs (cohort, editorials, case reports, review articles, single arm studies) were excluded. Studies with polypectomy of $<10 \mathrm{~mm}$ polyps or mixed results without subgroup analysis for $\geq 10 \mathrm{~mm}$ polyps were also excluded.

\section{Data collection}

Data was extracted and tabulated using Microsoft Excel (Microsoft, Redmond, Washington, United States) by 2 independent reviewers (M.G. and M.A.). Any conflict/ discrepancy was resolved through mutual discussion. Data for the following was obtained: study characteristics (publication year, country); demographics (age, male sex); mean/median polyp size; type of polypectomy; polyp pathology (adenoma including high-grade lesions, carcinoma, serrated lesions [sessile serrated adenomas, traditional serrated adenoma, and/ or proximal hyperplastic polyps], benign/other); proximal polyp (from cecum to transverse colon); and outcomes.

\section{Statistical analysis}

Primary outcome was DPPB within the follow-up period. Secondary outcomes included pain, post-polypectomy syndrome (PPS), and perforation. The outcomes were generated as event over total population in the respective group i.e., HG and SG. Intention-to-treat protocol was used where outcomes were generated based on original randomization/ allocation of patients to study groups regardless of study completion. Pooled rates of outcomes were compared using DerSimonian-Laird/Random effects model and relative risk (RR) with 95\% confidence interval (CI) were calculated. Forrest plot for each outcome and statistical analysis was conducted using Comprehensive Meta-Analysis (Biostat, Englewood, USA) and SPSS v26 (IBM, Armonk, New York, United States). The $I^{2}$ statistic was used as test for heterogeneity and value of $>50 \%$ was considered as substantial heterogeneity $[8,9]$. A subgroup analysis was also performed for studies that provided polypectomy data for $\geq 20 \mathrm{~mm}$ polyps. A P-value of $<0.05$ was considered statistically significant for all outcomes. Adherence to Preferred Reporting Items for Systematic Reviews and MetaAnalyses (PRISMA) guidelines were observed for the purpose of the study. Grading of Recommendations Assessment, Development and Evaluation (GRADE) approach to assess the certainty of evidence (HIGH, MODERATE, LOW, VERY LOW) for each outcome was utilized [10]. The anticipated absolute effect was defined as the risk in the intervention group (and its 95\% confidence interval) based on the assumed risk in the comparison group and the relative effect of the intervention (and its 95\%CI). Definitions of variables are provided in Supplementary Table 2.

\section{Bias assessment}

The risk of bias in each individual study was assessed using the Cochrane Risk of bias tools for RCTs [11]. Publication bias was assessed based on visual inspection of the funnel plot (qualitative) and Egger's regression analysis (quantitative). Risk of bias assessment is provided in Supplementary Table 3.

\section{Results}

A total of 261 studies were identified in our analysis based on our previously defined search strategy, after excluding all duplicates (Fig. 1). After screening, a total of 6 studies met our 


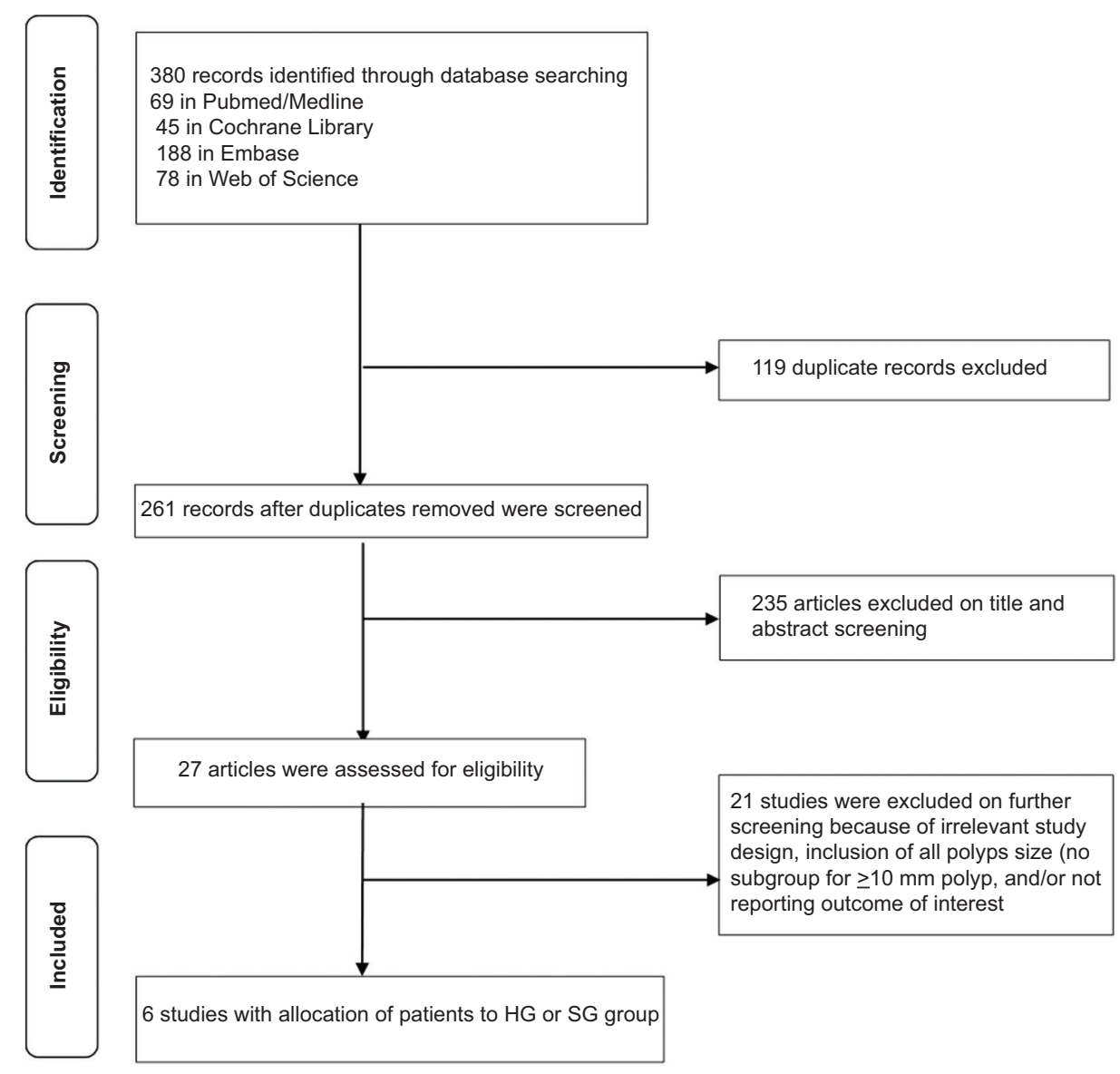

Figure 1 Flow diagram representing selection of studies HG, hemoclip group; SG, standard/control group

inclusion criteria (Table 1). Publication bias was difficult to assess given the low number of studies with Egger's $P$ value of 0.67 (Fig. 2). Dokoshi et al met the inclusion criteria for polyp size, however the outcomes were assessed based on per polyp analysis and not on per patient analysis and therefore their study was excluded. The overall risk of bias across all RCTs was high as highlighted in Table 2.

\section{Study details and demographics}

Study details and demographics are summarized in Tables 1 and 2. The total number of patients in the analysis was 2703 (with 1345 in SG vs. 1358 in HG group respectively). Both groups were similar in terms of age range (58-72 vs. $57-73$ years) and male sex ( $74 \%$ vs. $70 \%$ ) (Table 2).

\section{Outcomes}

Primary and secondary outcomes are displayed in Table 3. The overall incidence of delayed bleeding was lower in HG
Table 1 Baseline characteristics of included studies

\begin{tabular}{lccccc}
\hline Study & Year & Type & Total & SG & HG \\
\hline Albeniz [20] & 2019 & RCT & 237 & 117 & 120 \\
Feagins [4] & 2019 & RCT & 1098 & 551 & 547 \\
Kouklakis [21] & 2009 & RCT & 64 & 32 & 32 \\
Pohl [7] & 2019 & RCT & 928 & 470 & 458 \\
Zhang [12] & 2015 & RCT & 348 & 174 & 174 \\
Osada [22] & 2016 & RCT & 28 & 14 & 14 \\
\hline $\begin{array}{l}\text { RCT, randomized controlled trial; HG, hemoclip group; SG, standard/control } \\
\text { group }\end{array}$ & & \multicolumn{5}{l}{} \\
\end{tabular}

compared to SG group for all LPs $\geq 10 \mathrm{~mm}$. (2.8\% vs. $5.6 \%$, RR 0.51, 95\%CI 0.35-0.76; $\mathrm{P}=0.01 ; I^{2}=0 \%$ ) (Fig. 3A). Similarly, the incidence was also lower in all polyps when the clip was applied in studies with polyp size $\geq 20 \mathrm{~mm}$ (4 studies) (RR 0.48 , $95 \%$ CI $0.30-0.77 ; \mathrm{P}=0.03 ; I^{2}=0 \%$ ) (Fig. $3 \mathrm{~B}$ ). The results of Fig. $3 \mathrm{~A}$ and $3 \mathrm{~B}$ are consistent.

The overall perforation was evaluated and compared among the 5 studies for polyps $\geq 10 \mathrm{~mm}$ polyp and did now show any statistical difference when SG was compared to HG $(0.644 \%$ vs. $1.03 \%$, RR $0.681,95 \%$ CI $\left.0.240-1.932 ; \mathrm{P}=0.722 ; I^{2}=0 \%\right)$ (Fig. 3C). 
Post-polypectomy syndrome was defined as pain, fever, leukocytosis, or other peritoneal signs. The overall incidence of post-polypectomy syndrome was evaluated in 3 studies and it was not significantly different between the 2 groups $(0.66 \%$ vs. 1.2\%, RR 0.792, 95\%CI 0.076-8.239; $\mathrm{P}=0.85 ; I^{2}=59.7 \%$ ) (Fig. 3D).

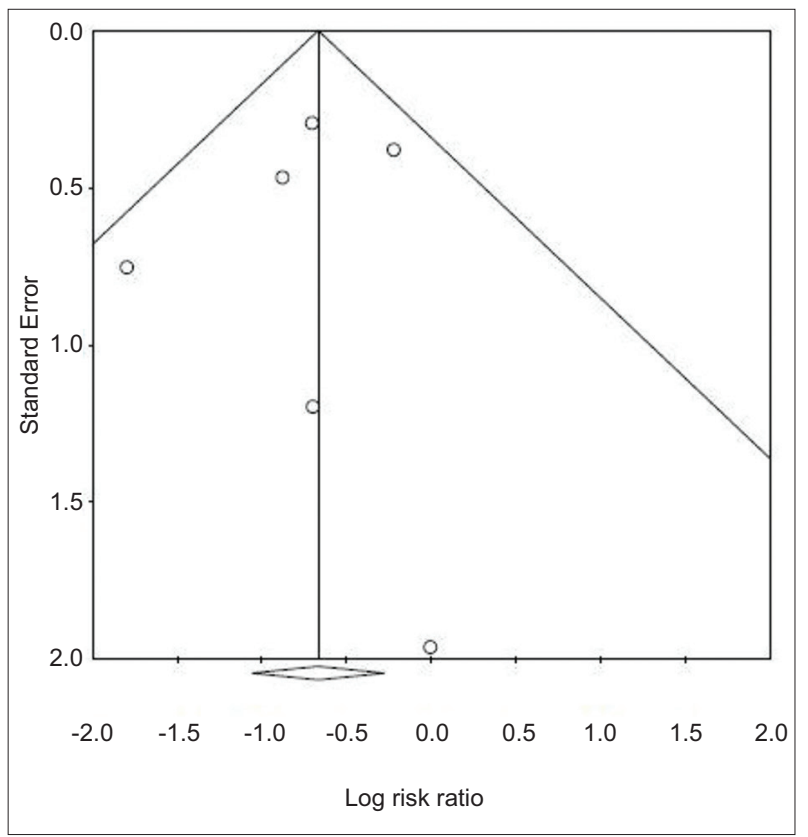

Figure 2 Funnel plot of publication bias assessment
Pain was defined as subjective. In Albeniz, pain was considered as when a patient required pharmacologic treatment or medical attention. Four studies evaluated subjective pain perception and no significant difference was observed between the 2 groups ( $0.64 \%$ vs. $4.20 \%$, RR 0.605 ; 95\%CI $0.102-3.601$; $\mathrm{P}=0.581 ; I^{2}=67.8 \%$ ) (Fig. $3 \mathrm{E}$ ).

A summary of the findings to assess the certainty of evidence using GRADE assessment is displayed in Supplementary Table 4 and description of certainty is provided in Supplementary Table 5.

\section{Discussion}

Our meta-analysis determined that the use of routine endoscopic clipping as a prophylactic modality reduces the risk of DPPB in LPs of $\geq 10 \mathrm{~mm}$. There was no significant difference between post-polypectomy syndrome, perforation or pain for SG and HG. These results were consistent on subgroup analysis of studies reporting data for polyps $\geq 20 \mathrm{~mm}$.

$\mathrm{DPPB}$, a frequent complication of polypectomy, can be a significant health burden for patients. Clipping is an effective modality that may prevent this complication. Several studies have evaluated their efficacy; however, the results have been non-homogenous, with a certain degree of variability. Zhang et al reported a reduction in the incidence of DPPB from $6.9 \%$ to $1.1 \%$, with the use of clipping in patients with LPs [12]. Similar results were also found by Pohl et al, who found

Table 2 Demographics of included studies

\begin{tabular}{|c|c|c|c|c|c|c|c|c|c|c|c|c|}
\hline \multirow[t]{2}{*}{ Characteristics } & \multicolumn{2}{|c|}{ Albeniz [20] } & \multicolumn{2}{|c|}{ Feagins [4] } & \multicolumn{2}{|c|}{ Kouklakis [21] } & \multicolumn{2}{|c|}{ Pohl [7] } & \multicolumn{2}{|c|}{ Zhang [12] } & \multicolumn{2}{|c|}{ Osada [22] } \\
\hline & SG & HG & SG & HG & SG & HG & SG & HG & SG & HG & SG & HG \\
\hline Mean/Median age, years & 71.1 & 72.7 & 64 & 64.5 & 58.8 & 57.9 & 65.1 & 65.1 & 64.2 & 67.9 & 66.2 & 68.6 \\
\hline Male \% & 77 & 81 & 91 & 92 & 44 & 47 & 60 & 58 & 61 & 63 & $36.4 \%$ & $64.3 \%$ \\
\hline Mean polyp size (mm) & 37.3 & 36.1 & 14 & 13.7 & 27 & 26.1 & 28 & 30 & NA & NA & NA & NA \\
\hline Proximal polyps (n) & 104 & 109 & 275 & 263 & 3 & 4 & 331 & 327 & 51 & 50 & 8 & 10 \\
\hline Adenoma (n) & 104 & 107 & 540 & 541 & NA & NA & 374 & 359 & NA & NA & NA & NA \\
\hline Adenocarcinoma (n) & 5 & 4 & 4 & 3 & NA & NA & 13 & 13 & NA & NA & 3 & 5 \\
\hline Serrated (n) & 7 & 8 & 55 & 47 & NA & NA & 105 & 115 & NA & NA & NA & NA \\
\hline Benign/Hyperplastic & NA & NA & 98 & 78 & NA & NA & 7 & 3 & NA & NA & NA & NA \\
\hline
\end{tabular}

HG, hemoclip group; SG, standard/control group; NA, not available

Table 3 Delayed bleeding and other complications

\begin{tabular}{|c|c|c|c|c|c|c|c|c|c|c|c|c|}
\hline \multirow[t]{2}{*}{ Complications } & \multicolumn{2}{|c|}{ Albeniz [20] } & \multicolumn{2}{|c|}{ Feagins $[4]$} & \multicolumn{2}{|c|}{ Kouklakis [21] } & \multicolumn{2}{|c|}{ Pohl [7] } & \multicolumn{2}{|c|}{ Zhang [12] } & \multicolumn{2}{|c|}{ Osada [22] } \\
\hline & SG & HG & SG & HG & SG & HG & SG & HG & SG & HG & SG & HG \\
\hline Delayed bleeding $\%(\mathrm{n} / \mathrm{N})$ & $14 / 117$ & $6 / 120$ & $15 / 551$ & $12 / 557$ & $02 / 32$ & $01 / 32$ & $33 / 470$ & $16 / 458$ & $12 / 174$ & $2 / 174$ & $0 / 14$ & $0 / 14$ \\
\hline Polypectomy syndrome & $0 / 117$ & $3 / 120$ & NA & NA & NA & NA & $1 / 470$ & $1 / 458$ & $8 / 174$ & $1 / 174$ & NA & NA \\
\hline Perforation & $1 / 117$ & $1 / 120$ & $0 / 551$ & $0 / 557$ & NA & NA & $6 / 470$ & $3 / 458$ & $1 / 174$ & $1 / 174$ & $0 / 14$ & $0 / 14$ \\
\hline Pain & $2 / 117$ & $6 / 120$ & NA & NA & $0 / 32$ & $0 / 32$ & $2 / 470$ & $1 / 458$ & $29 / 174$ & $5 / 174$ & NA & NA \\
\hline
\end{tabular}

HG, hemoclip group; SG, standard/control group; NA, not applicable 


\section{A}

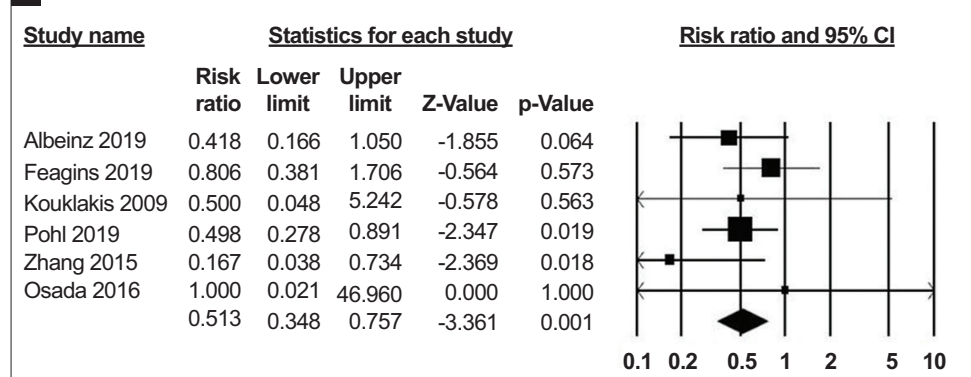

B

Favours HG Favours SG

\begin{tabular}{|c|c|c|c|c|c|}
\hline \multicolumn{6}{|l|}{ Meta Analysis } \\
\hline \multirow[t]{2}{*}{$\underline{\text { Study name }}$} & \multicolumn{5}{|c|}{ Statistics for each study } \\
\hline & $\begin{array}{l}\text { Risk } \\
\text { ratio }\end{array}$ & $\begin{array}{l}\text { Lower } \\
\text { limit }\end{array}$ & $\begin{array}{l}\text { Upper } \\
\text { limit }\end{array}$ & Z-Value & p-Value \\
\hline Albeinz 2019 & 0.418 & 0.166 & 1.050 & -1.855 & 0.06 \\
\hline Kouklakis 2009 & 0.500 & 0.048 & 5.242 & -0.578 & 0.563 \\
\hline Pohl 2019 & 0.498 & 0.278 & 0.891 & -2.347 & 0.01 \\
\hline \multirow[t]{2}{*}{ Osada 2016} & 1.000 & 0.021 & 46.960 & 0.000 & 1.000 \\
\hline & 0.480 & 0.297 & 0.774 & -3.007 & 0.003 \\
\hline
\end{tabular}

C

Risk ratio and $95 \% \mathrm{Cl}$

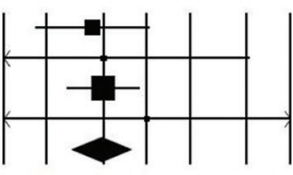

$\begin{array}{lllllll}0.1 & 0.2 & 0.5 & 1 & 2 & 5 & 10\end{array}$

Favours HG Favours SG

\begin{tabular}{|c|c|c|c|c|c|}
\hline \multicolumn{6}{|l|}{ Meta Analysis } \\
\hline \multirow[t]{2}{*}{ Study name } & \multicolumn{5}{|c|}{ Statistics for each study } \\
\hline & $\begin{array}{l}\text { Risk } \\
\text { ratio }\end{array}$ & $\begin{array}{l}\text { Lower } \\
\text { limit }\end{array}$ & $\begin{array}{l}\text { Upper } \\
\text { limit }\end{array}$ & Z-Value & \\
\hline Albeinz 2019 & 0.975 & 0.062 & 15.406 & -0.018 & \\
\hline Feagins 2019 & 1.007 & 0.020 & 50.675 & 0.004 & \\
\hline Pohl 2019 & 0.513 & 0.129 & 2.039 & -0.948 & \\
\hline Zhang 2015 & 1.000 & 0.063 & 15.860 & 0.000 & \\
\hline \multirow{2}{*}{ Osada 2016} & 1.000 & 0.021 & 46.960 & 0.000 & \\
\hline & 0.681 & 0.240 & 1.932 & -0.722 & \\
\hline
\end{tabular}

D

Favours HG Favours SG

\begin{tabular}{|c|c|c|c|c|}
\hline \multicolumn{5}{|c|}{ Meta Analysis } \\
\hline \multicolumn{2}{|c|}{ Study name } & \multicolumn{3}{|c|}{ Statistics for each study } \\
\hline & $\begin{array}{l}\text { Risk } \\
\text { ratio }\end{array}$ & $\begin{array}{l}\text { Lower } \\
\text { limit }\end{array}$ & $\begin{array}{l}\text { Upper } \\
\text { limit }\end{array}$ & \\
\hline Albeinz & 6.826 & 0.356 & 130.728 & \\
\hline Pohl & 1.026 & 0.064 & 16.357 & \\
\hline \multirow[t]{2}{*}{ Zhang } & 0.125 & 0.016 & 0.989 & \\
\hline & 0.792 & 0.076 & 8.239 & \\
\hline
\end{tabular}

E

Risk ratio and $95 \% \mathrm{Cl}$
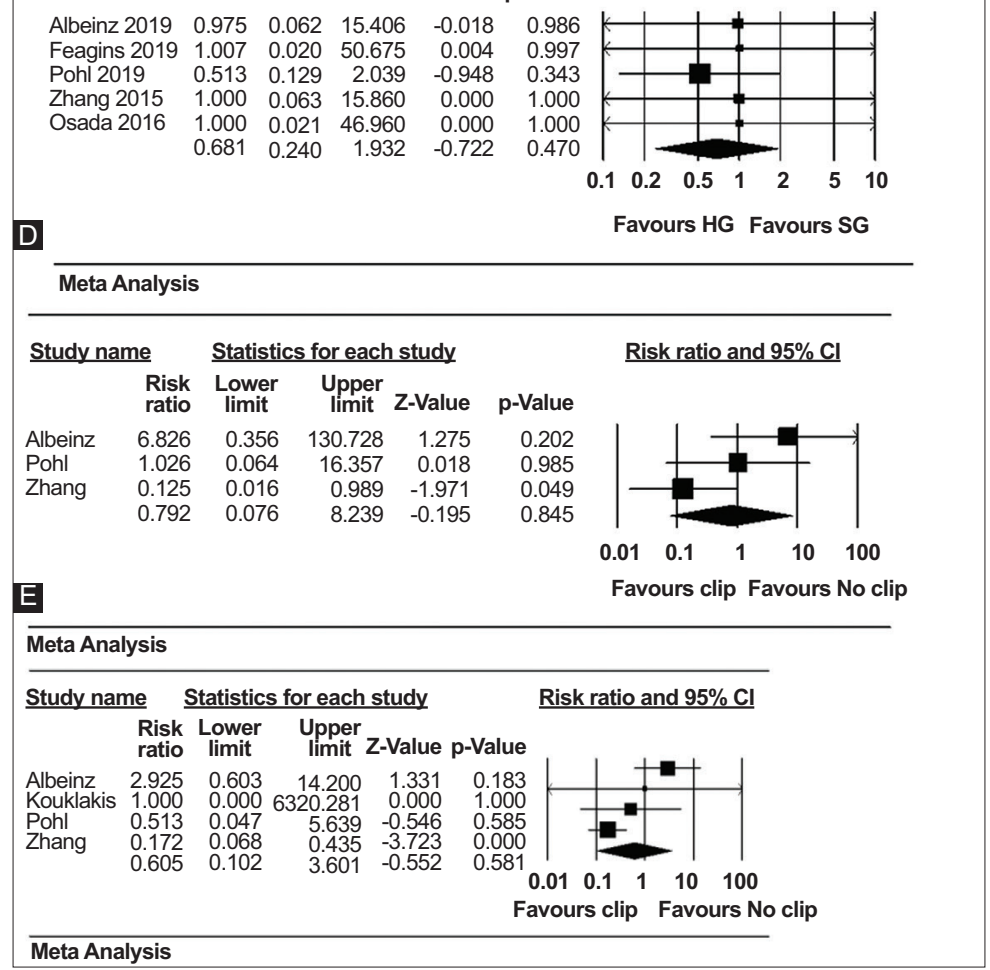

Figure 3 (A) Forest plot comparing delayed bleeding in hemoclip vs. standard/control group for all large polyps $\geq 10 \mathrm{~mm}$. (B) Forest plot comparing delayed bleeding in hemoclip vs. standard/control group for all large polyps $\geq 20 \mathrm{~mm}$. (C) Forest plot comparing perforation rates for polyps $\geq 10 \mathrm{~mm}$. (D) Forest plot comparing post-polypectomy syndrome for polyps $\geq 10 \mathrm{~mm}$. (E) Forest plot comparing subjective pain perception for polyps $\geq 10 \mathrm{~mm}$

CI, confidence interval 
the incidence rate of DPPB to be twice as high in patients who did not undergo clipping in comparison to patients who underwent clipping (7.1\% vs. 3.5\%) [7]. A previously conducted randomized trial by Shioji et al found no evidence on the reduction in DPPB. However, the majority (76.9\%) of the recruited patients had undergone polypectomy of small polyps $(<10 \mathrm{~mm})$, which have a lower tendency to bleed [13]. LPs on the other hand pose a complex problem as they have a higher tendency to cause DPPB. Dokoshi et al, in a RCT, reported higher bleeding rates and procedural time for polyps $\geq 20 \mathrm{~mm}$ with no other factor affecting the bleeding rate [14]. We excluded this study because the outcomes were determined based on the bleeding per polyp.

A recent analysis by Spadaccini et al showed a significant correlation between clipping of LPs $(\geq 20 \mathrm{~mm})$ and the reduced risk of DPPB [15]. This is similar to our findings, however there is a distinction in our classification of polyps. We considered all polyps $\geq 10 \mathrm{~mm}$ as large, as this correlates to an elevated risk of DPPB, when stratifying based on polyp size and are a well-established, independent risk factor for DPPB $[2,3,6]$. Hence, it is important to establish the utility of hemoclips in patients with polyp sizes $\geq 10 \mathrm{~mm}$. Our analysis provided evidence showing the benefit of clipping all polyps $\geq 10 \mathrm{~mm}$. Furthermore, our study evaluated all the remaining parameters such as incidences of overall bleeding, perforation, pain and post-polypectomy syndrome based on this population subset. Our findings also help explain the variability in results of previously conducted RCTs and systematic reviews due to the comparison of heterogeneous populations, without stratifying the polyp size.

Polyp location has also been a well-known risk factor for DPPB, although there have been contradictory reports. Amongst studies that found a significant correlation, proximal or right sided polyps were found to have a higher tendency to bleed compared to their distal or left-sided counterparts [16-19]. There has been speculation on whether the histology and morphology of a polyp may play a role in the development of DPPB, however they have not as yet been established as significant risk factors [17-19]. Amongst histological types, adenomas and hyperplastic polyps have been reported to have higher incidences of DPPB, and, in regards to morphology, sessile polyps compared to pedunculated have been reported to have a higher incidence of DPPB [5]. In our analysis, due to lack of data, we could not evaluate the association of the previous factors with DPPB, although we found a higher proportion of proximal polyps and adenomas occurring with DPPB.

As with all systematic reviews, our review has its strengths and its limitations. Our reviews strengths include the incorporation of a wide variety of data, helping to reduce sampling bias and increase generalizability. We conducted an extensive search from all major databases, and enrolled up to 261 studies as part of our initial search strategy, and, after early and final screening, there were 6 RCT studies that met our inclusion and exclusion criteria. Since our research solely comprised data from RCTs, the chances of confounding bias occurring is reduced. We also found a significant correlation between the intervention and the outcome, and a considerably low amount of heterogeneity within the studies, when evaluating our primary outcome, i.e., the incidence of DPPB.

Although our study provides strong evidence pertaining to the use of clipping as an effective method of achieving hemostasis, there are a few limitations. First, while polyp size has a high correlation with the incidence of DPPB, we did not take into account other risk factors which may have contributed to the incidence of DPPB. Several studies have highlighted age, hypertension and the use of anticoagulants influencing the incidence of DPPB. In addition, variables such as polyp type and location also play a crucial role. Further studies need to be conducted to evaluate the impact of hemoclip when these risk factors are used as independent variables. Second, amongst 2 of our examined outcomes, post-polypectomy syndrome and postprocedure pain, there was considerable heterogeneity within the results. This may be attributed to the varying study designs and the diverse population groups, such as the differences in endoscopists' practices (e.g., clip type), distinct clinical settings, and the use of anticoagulants prior to treatment.

In conclusion, the use of hemoclips in achieving hemostasis for LPs has a beneficial effect and appears to prevent DPPB. This reinforces the routine clinical practice of using hemoclips in polypectomy procedures. Further studies are required to establish their effectiveness in patients with additional risk factors such as anticoagulation or hypertension, and to establish their priority compared to different hemostasis procedures.

\section{Summary Box}

\section{What is already known:}

- Polypectomy can lead to post-procedure hemorrhage, particularly delayed post-procedure bleeding (DPPB)

- Data on the efficacy of hemoclips to control DPPB vary

- Established risk factors can lead to increased incidences of DPPB

\section{What the new findings are:}

- When stratified for size, hemoclips were effective in reducing the rates of $\mathrm{DPPB}$

- Hemoclips did not have a statistically different effect on other complications of polypectomy

- Stratifying for different risk factors of bleeding can explain the variety of results produced by previously conducted research

\section{References}

1. Kolligs F. Diagnostics and epidemiology of colorectal cancer. Visc Med 2016;32:158-164.

2. Sawhney MS, Salfiti N, Nelson DB, Lederle FA, Bond JH. Risk factors for severe delayed postpolypectomy bleeding. Endoscopy 
2008;40:115-119.

3. Kim HS, Kim TI, Kim WH, et al. Risk factors for immediate postpolypectomy bleeding of the colon: a multicenter study. Am J Gastroenterol 2006;101:1333-1341.

4. Feagins LA, Smith AD, Kim D, et al. Efficacy of prophylactic hemoclips in prevention of delayed post-polypectomy bleeding in patients with large colonic polyps. Gastroenterology 2019;157:967976.e1.

5. Choung BS, Kim SH, Ahn DS, et al. Incidence and risk factors of delayed postpolypectomy bleeding: a retrospective cohort study. J Clin Gastroenterol 2014;48:784-789.

6. Boumitri C, Mir FA, Ashraf I, et al. Prophylactic clipping and postpolypectomy bleeding: a meta-analysis and systematic review. Ann Gastroenterol 2016;29:502-508.

7. Pohl H, Grimm IS, Moyer MT et al. Clip closure prevents bleeding after endoscopic resection of large colon polyps in a randomized trial. Gastroenterology 2019;157:977-984.e3.

8. Shuster J.J. Review: Cochrane handbook for systematic reviews for interventions. Version 5.1.0, John Wiley \& Sons, 2011.

9. Higgins JPT, Thompson SG, Deeks JJ, Altman DG. Measuring inconsistency in meta-analyses. BMJ 2003;327:557-560.

10. Puhan MA, Schunemann HJ, Murad MH, et al. A GRADE Working Group approach for rating the quality of treatment effect estimates from network meta-analysis. BMJ 2014;349:g5630.

11. Higgins JPT, Altman DG, Gotzsche PC, et al. The Cochrane Collaboration's tool for assessing risk of bias in randomised trials. BMJ 2011;343:d5928-d5928.

12. Zhang Q, Han B, Xu J, Gao P, Shen Y. Clip closure of defect after endoscopic resection in patients with larger colorectal tumors decreased the adverse events. Gastrointest Endosc 2015;82:904-909.

13. Shioji K, Suzuki Y, Kobayashi M, et al. Prophylactic clip application does not decrease delayed bleeding after colonoscopic polypectomy. Gastrointest Endosc 2003;57:691-694.
14. Dokoshi T, Fujiya M, Tanaka K, et al. A randomized study on the effectiveness of prophylactic clipping during endoscopic resection of colon polyps for the prevention of delayed bleeding. Biomed Res Int 2015;2015:490272.

15. Spadaccini M, Albéniz E, Pohl H, et al. Prophylactic clipping after colorectal endoscopic resection prevents bleeding of large, proximal polyps: meta-analysis of randomized trials. Gastroenterology 2020;159:148-151.

16. Buddingh KT, Herngreen T, Haringsma J, et al. Location in the right hemi-colon is an independent risk factor for delayed postpolypectomy hemorrhage: a multi-center case-control study. Am J Gastroenterol 2011;106:1119-1124.

17. Jaruvongvanich V, Prasitlumkum N, Assavapongpaiboon B, et al. Risk factors for delayed colonic post-polypectomy bleeding: aA systematic review and meta-analysis. Int J Colorectal Dis 2017;32:1399-1406.

18. Watabe H, Yamaji Y, Okamoto M, et al. Risk assessment for delayed hemorrhagic complication of colonic polypectomy: polyp-related factors and patient-related factors. Gastrointest Endosc 2006;64:73-78.

19. Moon HS, Park SW, Kim DH, et al. Only the size of resected polyps is an independent risk factor for delayed postpolypectomy hemorrhage: a 10-year single-center case-control study. Ann Coloproctol 2014;30:182-185.

20. Albeniz E, Alvarez MA, Espinos JC, et al. Clip Closure After Resection of Large Colorectal Lesions With Substantial Risk of Bleeding. Gastroenterology 2019;157:1213-1221

21. Kouklakis G, Mpoumponaris A, Gatopoulou A, et al. Endoscopic resection of large pedunculated colonic polyps and risk of postpolypectomy bleeding with adrenaline injection versus endoloop and hemoclip: a prospective, randomized study. Surgical Endosc 2009;23:2732-2737.

22. Osada T, Sakamoto N, Ritsuno H, et al. Closure with clips to accelerate healing of mucosal defects caused by colorectal endoscopic submucosal dissection. Surgical Endosc 2016;30:4438-4444. 


\section{Supplementary material}

Supplementary Table 1 Embase search strategy

\begin{tabular}{|c|c|c|}
\hline No. & Query & Results \\
\hline 1. & $\begin{array}{l}\text { polypectom* OR postpolypectom* OR 'post polypectom*' OR 'endoscopic polypectomy'/exp OR 'polypectomy'/exp OR } \\
\text { 'intestine polyp'/exp/dm_su OR 'intestine carcinoma'/exp/dm_su }\end{array}$ & 30955 \\
\hline 2. & 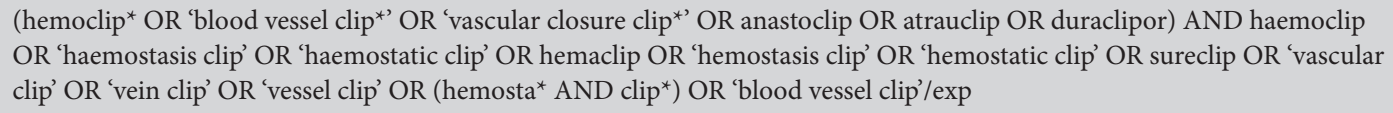 & 4265 \\
\hline 3. & $\begin{array}{l}\text { 'postoperative bleed }{ }^{\star} \text { OR 'postoperative blood loss' OR 'postoperative haemorrhage' OR 'postoperative haemorrhagia*’ OR } \\
\text { 'postoperative hemorrhage' OR 'postoperative hemorrhagia*' OR bleed OR hemostat* OR 'postoperative hemorrhage'/exp } \\
\text { OR 'gastrointestinal hemorrhage'/exp }\end{array}$ & 621298 \\
\hline 4. & \#1 AND \#2 AND \#3 & 308 \\
\hline 5. & \#4 NOT ('editorial'/it OR 'review'/it OR 'short survey'/it) & 269 \\
\hline 6. & $\begin{array}{l}\text { \#5 NOT ('animal experiment'/de OR 'animal model'/de OR 'animal tissue'/de OR 'case report'/de OR 'case study'/de OR } \\
\text { 'meta analysis'/de OR 'nonhuman'/de OR 'porcine model'/de OR 'practice guideline'/de OR 'systematic review'/de) }\end{array}$ & 188 \\
\hline
\end{tabular}

Supplementary Table 2 Definition of variables across studies

\begin{tabular}{|c|c|c|c|c|c|c|}
\hline Variables & Albeniz [20] & Feagins [4] & Kouklakis [21] & Pohl [7] & Zhang [12] & Osada [22] \\
\hline Polypectomy & $\begin{array}{l}\text { Injection-assisted } \\
\text { EMR was } \\
\text { performed }\end{array}$ & $\begin{array}{l}\text { Injection-assisted } \\
\text { EMR was } \\
\text { performed }\end{array}$ & $\begin{array}{l}\text { In group A, injection- } \\
\text { assisted EMR was } \\
\text { performed. In group } \\
\text { B snaring followed by } \\
\text { EMR was performed. } \\
\text { Smaller polyps } \\
\text { were removed with } \\
\text { conventional snare } \\
\text { polypectomy. }\end{array}$ & $\begin{array}{l}\text { Injection-assisted } \\
\text { EMR was performed }\end{array}$ & $\begin{array}{l}\text { Injection followed } \\
\text { by EMR. If the } \\
\text { lesion exceeded } 2.0 \\
\mathrm{~cm} \text {, conventional } \\
\text { EMR with } \\
\text { circumferential } \\
\text { incision or ESD was } \\
\text { used. }\end{array}$ & $\begin{array}{l}\text { Injection- } \\
\text { assisted } \\
\text { EMR was } \\
\text { performed with } \\
\text { circumferential } \\
\text { incision }\end{array}$ \\
\hline Clip closure & $\begin{array}{l}\text { Defined as } \\
\text { complete closure, } \\
\text { partial closure and } \\
\text { failed closure }\end{array}$ & $\begin{array}{l}\text { Defined as either } \\
\text { complete closure } \\
\text { with hemoclips or } \\
\text { if the defect could } \\
\text { only be partially } \\
\text { closed }\end{array}$ & $\begin{array}{l}\text { Complete closure of } \\
\text { mucosal defect }\end{array}$ & $\begin{array}{l}\text { Complete closure of } \\
\text { mucosal defect }\end{array}$ & $\begin{array}{l}\text { The whole resection } \\
\text { site was closed } \\
\text { completely with } \\
\text { clips and sutures }\end{array}$ & $\begin{array}{l}\text { Mucosal defects } \\
\text { post-ESD } \\
\text { were closed } \\
\text { completely } \\
\text { using clips }\end{array}$ \\
\hline Bleeding & $\begin{array}{l}\text { Defined as } \\
\text { clinically evident } \\
\text { bleeding that } \\
\text { required medical } \\
\text { attention within } \\
15 \text { days after the } \\
\text { colonoscopy }\end{array}$ & $\begin{array}{l}\text { Defined as the } \\
\text { occurrence of } \\
\text { delayed PPB } \\
\text { (rectal bleeding } \\
\text { within } 30 \text { days } \\
\text { after polypectomy) }\end{array}$ & $\begin{array}{l}\text { Bleeding was defined } \\
\text { as bleeding occurring } \\
\text { between } 24 \mathrm{~h} \\
\text { and } 30 \text { days after } \\
\text { polypectomy } \\
\text { presenting as } \\
\text { hematochezia }\end{array}$ & $\begin{array}{l}\text { Defined as a severe } \\
\text { bleeding event after } \\
\text { the patient } \\
\text { left the endoscopy } \\
\text { unit and within } \\
30 \text { days after } \\
\text { completion } \\
\text { of the colonoscopy }\end{array}$ & $\begin{array}{l}\text { DPPB was defined } \\
\text { as bleeding that } \\
\text { resulted in overt } \\
\text { hematochezia } 6 \\
\text { hours to } 30 \text { days } \\
\text { after EMR or ESD }\end{array}$ & $\begin{array}{l}\text { Defined as overt } \\
\text { rectal bleeding } \\
\text { that occurred } \\
\text { during } 4 \text { weeks } \\
\text { post-ESD }\end{array}$ \\
\hline $\begin{array}{l}\text { Post- } \\
\text { polypectomy } \\
\text { syndrome }\end{array}$ & $\begin{array}{l}\text { Defined by } \\
\text { symptoms of pain, } \\
\text { fever, } \\
\text { leukocytosis, } \\
\text { peritoneal } \\
\text { tenderness, and } \\
\text { guarding }\end{array}$ & & & $\begin{array}{l}\text { Defined by } \\
\text { symptoms of pain, } \\
\text { fever, } \\
\text { leukocytosis, } \\
\text { peritoneal } \\
\text { tenderness, and } \\
\text { guarding }\end{array}$ & $\begin{array}{l}\text { Defined by } \\
\text { symptoms of pain, } \\
\text { fever, } \\
\text { leukocytosis, } \\
\text { peritoneal } \\
\text { tenderness, and } \\
\text { guarding }\end{array}$ & \\
\hline $\begin{array}{l}\text { Post- } \\
\text { procedure } \\
\text { pain }\end{array}$ & $\begin{array}{l}\text { Pain was } \\
\text { considered when a } \\
\text { patient required } \\
\text { pharmacologic } \\
\text { treatment or } \\
\text { medical attention }\end{array}$ & Subjective & $\begin{array}{l}\text { Subjective based on } \\
\text { the patient follow } \\
\text { ups at outpatient } \\
\text { department }\end{array}$ & Subjective & Subjective & Subjective \\
\hline
\end{tabular}

EMR, endoscopic mucosal resection; ESD, endoscopic submucosal dissection; PPB, post-polypectomy bleeding 
Supplementary Table 3 Risk of bias included in randomized controlled trials

\begin{tabular}{|c|c|c|c|c|c|c|}
\hline Study & $\begin{array}{l}\text { Random sequence } \\
\text { generation } \\
\text { (selection bias) }\end{array}$ & $\begin{array}{l}\text { Allocation } \\
\text { concealment } \\
\text { (selection bias) }\end{array}$ & $\begin{array}{l}\text { Blinding of participants } \\
\text { and personnel } \\
\text { (performance bias) }\end{array}$ & $\begin{array}{l}\text { Blinding of outcome } \\
\text { assessment } \\
\text { (detection bias) }\end{array}$ & $\begin{array}{l}\text { Selective reporting } \\
\text { (reporting bias) }\end{array}$ & $\begin{array}{l}\text { Other } \\
\text { bias }\end{array}$ \\
\hline Albeniz & Low & Low & High & High & Low & Low \\
\hline Feagins & Low & Low & High & High & Low & Low \\
\hline Kouklakis & Low & Unclear & High & Low & Unclear & Low \\
\hline Pohl & Low & Low & High & High & Low & Low \\
\hline Zhang & Low & Low & High & Low & Low & Low \\
\hline Osada & Unclear & Low & High & Low & Low & Low \\
\hline
\end{tabular}

Supplementary Table 4 Summary of findings

\begin{tabular}{|c|c|c|c|c|c|}
\hline \multirow[t]{2}{*}{ Outcomes } & \multicolumn{2}{|c|}{ Anticipated absolute Effects* $(95 \% \mathrm{CI})$} & \multirow{2}{*}{$\begin{array}{l}\text { Relative effect } \\
\quad(95 \% \mathrm{CI})\end{array}$} & \multirow{2}{*}{$\begin{array}{c}\text { Number of } \\
\text { participants (studies) }\end{array}$} & \multirow{2}{*}{$\begin{array}{l}\text { Certainty of the } \\
\text { evidence (GRADE) }\end{array}$} \\
\hline & $\begin{array}{l}\text { Risk with Standard } \\
\text { group }\end{array}$ & $\begin{array}{l}\text { Risk with Hemoclip } \\
\text { group }\end{array}$ & & & \\
\hline $\begin{array}{l}\text { Delayed post-polypectomy } \\
\text { bleeding }(>10 \mathrm{~mm})\end{array}$ & 56 per 1000 & $\begin{array}{c}29 \text { per } 1,000 \\
(19-42)\end{array}$ & $\begin{array}{c}\text { RR } 0.513 \\
(0.348-0.757\end{array}$ & $\begin{array}{c}2703 \\
(6 \mathrm{RCTs})\end{array}$ & $\begin{array}{l}\oplus \oplus \oplus \oplus \\
\mathrm{HIGH}\end{array}$ \\
\hline $\begin{array}{l}\text { Delayed post-polypectomy } \\
\text { bleeding (>20 } \mathrm{mm})\end{array}$ & 81 per 1000 & $\begin{array}{l}64 \text { per } 1,000 \\
(6-670)\end{array}$ & $\begin{array}{c}\text { RR } 0.792 \\
(0.076-8.239)\end{array}$ & $\begin{array}{c}1227 \\
(4 \mathrm{RCTs})\end{array}$ & $\begin{array}{l}\oplus \oplus \oplus \oplus \\
\mathrm{HIGH}\end{array}$ \\
\hline Post-polypectomy syndrome & 12 per 1000 & 11 per $1,000(0-41)$ & $\begin{array}{c}\text { RR } 1.020 \\
(0.991-1.051)\end{array}$ & $\begin{array}{c}1513 \\
(3 \mathrm{RCTs})\end{array}$ & $\begin{array}{c}\oplus \oplus \oplus \bigcirc \\
\text { MODERATE }\end{array}$ \\
\hline Pain & 42 per 1,000 & $\begin{array}{l}25 \text { per } 1,000 \\
(4-150)\end{array}$ & $\begin{array}{c}\text { RR } 0.605 \\
(0.102-3.601)\end{array}$ & $\begin{array}{c}1577 \\
(4 \mathrm{RCTs})\end{array}$ & $\begin{array}{c}\oplus \oplus \oplus \bigcirc \\
\text { MODERATE }\end{array}$ \\
\hline Perforation & 6 per 1,000 & $\begin{array}{l}4 \text { per } 1,000 \\
(1-12)\end{array}$ & $\begin{array}{c}\text { RR } 0.681 \\
(0.240-1.932)\end{array}$ & $\begin{array}{c}2646 \\
(5 \mathrm{RCTs})\end{array}$ & $\begin{array}{l}\oplus \oplus \oplus \oplus \\
\mathrm{HIGH}\end{array}$ \\
\hline
\end{tabular}

${ }^{*}$ The risk in the intervention group (and its $95 \% \mathrm{CI}$ ) is based on the assumed risk in the comparison group and the relative effect of the intervention (and its $95 \% \mathrm{CI}$ ) $C I$, confidence interval, RR risk ratio; $R C T$, randomized controlled trial

Supplementary Table 5 GRADE Working Group grades of evidence

\begin{tabular}{ll}
\hline High certainty & $\begin{array}{l}\text { We are very confident that the true effect } \\
\text { lies close to that of the estimate of the effect }\end{array}$ \\
Moderate certainty & $\begin{array}{l}\text { We are moderately confident in the effect } \\
\text { estimate: The true effect is likely to be close } \\
\text { to the estimate of the effect, but there is a } \\
\text { possibility that it is substantially different }\end{array}$ \\
Low certainty & $\begin{array}{l}\text { Our confidence in the effect estimate is } \\
\text { limited: The true effect may be substantially } \\
\text { different from the estimate of the effect }\end{array}$ \\
Very low certainty & $\begin{array}{l}\text { We have very little confidence in the effect } \\
\text { estimate: The true effect is likely to be } \\
\text { substantially different from the estimate } \\
\text { of effect }\end{array}$ \\
\hline
\end{tabular}

